not to be compared with the fluorescence developed by the discharge in any known gas. The yellow and green lines can be seen and measured in the spectroscope in full daylight.

The photographs give the following lines wave-lengths, $\lambda \lambda$ 579,577 and $546 ; 436,405,354,3^{1} 3$ and $3^{12}$ (ultra-riolet); one can see two violet lines besides, 420 and 416 , scarcely visible, and the lines 385 and $35^{8}$.

The spectrum observed at the end of fifteen hours was maintained during thirty consecutive hours.

Although advantage has been taken of photography for the registration of these phenomena, care must be taken not to confound such effects, observed in the daytime and under normal pressure, with the glows developed by the discharge in very rarefied gases, such as are generally observed in a spectroscope.

The meaning of these lines is as follows:

The line $\lambda 579$ is simply one of the lines visible in daylight, and under normal pressure, which I had describer in Comptes rendus (t. cxx. p. 8oo), pointing out that it was probably double. The lines $\lambda \lambda 5^{80} \cdot \mathrm{I}$ and $577^{\circ} \mathrm{I}$ described in the spectrum of rarefied argon, by Mr. Crookes (Jan. 24, I895), must be compared with them.

Line $\lambda 546$ is also described (547) in my preceding note, and answers to a strong line $545^{\circ} 6$ attributed to the spectrum of rarefied argon by Mr. Crookes. M. Deslandres has recognised the same lines in the spectrum of rarefied argon, which he had prepared by means of lithium. I have rerified, by juxtaposition, the coincidence of the last line of rarefied argon with that of my tube.

I have also announced line 436 , found again in the photograph, and very close to $434^{\circ} 5$ of rarefied argon (Crookes). The lines 420 and 416 coincide with the very strong lines $420^{\circ} \mathrm{I}-$ $419^{\circ} 8$ and $415^{\circ} .66$ of rarefied argon (Crookes). The line 405 can be identified with the line $404^{\circ} 4$ of Crookes (argon). I have verified the coincidence. Line 385 coincides with Crookes strong line $385 \cdot 15$ (argon). Line 354 , with a group of strong lines at $354^{\circ} 7-353^{\circ} 4$ of argon (Crookes). Line 358 with Crookes' group of strong lines $35^{\circ} 7^{\circ}-357^{\circ} 5$ (argon).

$\lambda 5^{16.5}$ is a hydrocarbon band; 313 and 312 are the lines of the vapour of mercury vapour.

None of these lines, as I have already stated, coincide either with the line of helium $(587.5)$ or with the principal line of the aurora borealis (557), although the latter is very near to a strong line of argon $\left(555^{\circ} 7\right)$. If the actual fluorescence is not the same as that of the aurora borealis, still its development, and the nearness of the preceding lines, establish a probable relation between this meteor and the existence of argon in the atmosphere.

Here a very important circumstance presents itself. While examining the table of argon lines, given by Mr. Crookes, certain lines were seen to coincide with certain lines of the vapour of mercury. The same coincidence is found in the straight lines visible in daylight, under the normal pressure, in the fluorescence developed during the reaction of benzene on argon. Such are, according to M. Deslandres, the yellow lines 579 and 577 ; also the very characteristic green line 546 , the blue line $43^{6}$, the violet line 405 , the ultra-violet line 354 . On the contrary, the lines $420,4 \mathrm{I} 6,385,35^{8}$, belong to argon only, the lines $3 \mathrm{I} 3$ and 312 to mercury.

M. Deslandres attributes the common lines to the presence of the vapour of merciury, either in rarefied argon, or in the fluorescent light obtained with benzene under normal pressure.

Nevertheless, as no known gas gives this fluorescence, or these lines, under normal pressure in operating with mercury, it is not possible to explain their production merely by the presence of this vapour alone. Otherwise it would not be understood why they did not show themselves in pure argon, in the presence of mercury under normal pressure, and that they would not produce themselves during the first moments of discharge, either with argon saturated with benzene, or with sulphide of carbon over mercury, or with nitrogen under the same conditions, where it combines with benzene and sulphide of carbon. On the cuntrary, with argon saturated with benzene, they develop themselves only at the end of several hours, and after the progressive transformation of the benzene into a series of compounds more and more condensed. It is one of these compounds which, immediately it is formed, unites itself both with argon and mercury, associated perhaps by reason of their common character of monatomic molecules. The fluoresence begins when there still exists a notable quantity of liquid benzene in the tubes; it is then accompanied by a diminution of gaseous volume.
This furorescence continues a rery long time, even after there is no apparent benzene; at last the fluorescence ceases to be visible in the daylight, in consequence of the very prolonged action of the discharge, which at last extinguishes the green tint, and brings back this gaseous system to a glow analogous to that of ordinary gases, this happens doubtless in consequence of the destruction of the last traces of benzene (or the products of intermediate condensation), which maintained the equilibrium of the dissociation of the system.

Once the green fluorescence is well established, the compound which derelop it are stable by themselves; even after twelve hours' break, if the apparatus has not been disturbed, it suffices to pass the discharge, to see that the fluorescence re-establishes itself with all its brilliancy in an instant. But it ceases so soon as the electric current is stopped.

But if the gas is separated from the condensed matter, the phenomenon cannot be immediately produced, either on the one or on the other. The gas alone, subjected to the action of thedischarge, puts on almost immediately a special violet fluorescence, risible in darkness, and which generally precedes the derelopment of the beautiful green fluorescence. Nevertheless this does not reproduce itself then, which seems to indicate that the condensed matter contains one of the products necessary to the equilibrium. If, on the other hand, new argon is reintroduced into the tube containing the condensed matter (free from visible benzene), the green fluorescence does not reproduce itself; but after some time, near the surface of the mercury, there appears, where the sparking is most intense, a local green tint, which gives the special lines, although not rery distinctly. This appearance is doubtless due to the existence (or to the regeneration) of a trace of benzene, more or less modified. In fact, if a few more drops of liquid benzene are added in the tube which contains the condensed matter and the new argon over mercury, half an hour is enough to make the green tint reappear in all its brilliancy. But if there is an excess of benzene, several hours are required for its reappearance.

These various observations, added to the limited character of the absorption of argon, demonstrate the existence of a complex state of equilibrium, in which at the same time argon, mercurs, and the elements of benzene, or rather a compound con. densed from it, are concerned.

\section{THE REFORM OF OUR WEIGHTS AND} $M E A S U R E S$.

THE Report of the Select Committee appointed to inquire whether any, and what, changes in the present system of weights and measures should be adopted, has been published as a Parliamentary paper.

Eridence from witnesses representing official, commercial, manufacturing, trade, educational, and professional interests was received by the Committee, and numerous corporations, School Boards, and other public bodies sent resolutions in favour of the adoption of the metrical system.

All the witnesses expressed a strong opinion as to the complicated and unsatisfactory condition of the present weights and measures in use, and of the distinct and serious drawback to British commence, especially in the foreign trade, which this system entails, differing as it does from the system (metrical) now adopted by almost every European nation, as well as by far the majority of non-European countries with which this kingdom trades. The evidence also showed that the home trade would be benefited if more simple and uniform standards of weights and measures than those now existing were adopted.

Woreover, strong evidence was brought forward as to the serious loss of time incurred by English school-children in having to learn the complicated system of tables of existing weights and measures, and the urgent need of the adoption of a simpler system. It was stated that no less than one year's school time would be saved if the metrical system were taught in place of that now in use.

Eridence from competent witnesses proved to the satisfaction of the Committee that a compulsory change from an old and com. plicated system to the metrical had taken place in Germany, Norway and Sweden, Switzerland, Italy, and many other European countries without serious opposition or inconvenience ; that this change was carried out in a comparatively short period; and that as soon as the simple character of the new system was understood it was appreciated by all classes of the population, 
and no attempt to use the old units or to return to the old system was made.

In the United States, where a system founded on the English units exists, a Commission is at present engaged in an investigation of the same character as that with which the Committee was charged, and the Federal Government has this year passed an Act rendering the metrical system compulsory for pharmacentical purposes.

The Committee believes that the adoption of the metrical system by England would greatly tend to render that system universal.

It is recommended :-

(a) That the metrical system of weights and measures be at once legalised for all purposes.

(b) That after a lapse of two years the metrical system be rendered compulsory by Act of Parliament.

(c) That the metrical system of weights and measures be taught in all public elementary schools as a necessary and integral part of arithmetic, and that decimals be introduced at an earlier period of the school curriculum than is the case at present.

\section{SCIENCE IN THE MAGAZINES.}

THIS month's Contemporary Rezieze is remarkably rich in articles of scientific interest. Mr. Herbert Spencer's thirc paper on professional institutions deals with the "Dancer and Musician." So far back as I 857, Mr. Spencer showed that, excluding movements which are reflex and involuntary, muscular movements in general are originated by feelings in general. "As a consequence of this psycho-physical law, the violent muscular motions of the limbs which cause bounds and gesticulations, as well as those strong contractions of the pectoral and rocal muscles which produce shouting and laughter, become the natural language of great pleasure." From the ways in which children manifest their joy were evolved the expressions of elated feeling with which peoples meet their conquering chief or king, and eventually the natural displays of joy came " to be observances used on all public occasions as demonstrations of allegiance, while, simultaneously, the irregular jumpings and gesticulations with unrhythmical shouts and cries, at first arising without concert, gradually by repetition became regularised into the measured movements we know as dances, and into the organised utterances constituting songs. Once more, it is easy to see that out of the groups of subjects thus led into irregular ovations, and by-and-by into regular laudatory receptions, there will eventually arise some who, distinguished by their skill, are set apart as dancers and singers, and presently acquire the prosessional character." In support of this interpretation evidence obtained from many nations is adduced, and the separation and secularisation of the twin professions of dancing and music are traced. Mr. G. F. Scott-Elliot writes in the same review on "The Best Route to Uganda." $\mathrm{He}$ is in favour of a route follo wing the line of the African lakes. The route enters the Zambesi at Chinde, and continues up the Zambesi and Lower Shiré as far as Chiromo, from whence a railway of approximately 120 miles would be required across the Shiré Highlands to Matope, from which point the Upper Shiré is navigable, and goods can be carried to the north end of Lake Nyassa. Here another railway would be required from Karonga to South Tanganika (240 miles). From the north end of Tanganika a line would run to Kagera. The Kagera river rises on the easterly flanks of the mountains to the east of Tanganika, and eventually falls into the Victoria Nyanza. A cataract is said to exist on the river, but even if this is so, and a length of line is required to avoid it, the cost of the whole line would only be about $f_{1}, 700,000$, or one-half that necessary for the Mombasa railway. Other considerations point clearly to the Lake route as the better of the two suggested lines. Prof. Lombroso contributes a paper on "Atavism and Erolution." He gives a number of instances of what he regards as atavistic phenomena in social life. "England," he says, " has succeeded in establishing a form of monarchy the most liberal in Europe; and is working out without disturbance the aims of Socialism. But, at the same time, she not only maintains the privileges of her Peers, but actually dresses them up, as well as her judges, in the wigs and robes of the Normans ; and still uses, on ceremonial occasions, the language of her ancient conquerors. ... Then this very positive and practical nation insists on retaining a system of weights, measures, and coins, which is opposed to that of all modern Europe, and is an obstacle

NO. I 34 I, VOL. 52 ] both to commercial exchange and to scientific research." $\mathrm{He}$ classifies recent inventions which are shown to be old as evidence of atavism, and explains the duplication by the dislike with which, according to him, human nature regards novelties. Too rapid advance in the arts provokes reaction and causes the tide of progress to ebb when it should be flowing. A sensible article on the "Physiology of Recreation" is contributed by Mr. Charles Roberts, in the course of which he gives the following classifica. tion of physical recreations according to their physiological value. Outdoor : running, athletics, games, skating, skipping, \&c. ; riding, rowing, swimming, walking, cycling, marching. Indoor : fencing and other military exercises with arms, boxing and wrestling, dancing, billiards, dumb-bells, machine gymnastics, trapeze and high gymnastics, singing and reading aloud, playing musical instruments. Recreations of a leisurely sort, physiologically considered, are:-Outdoor: natural history, gardening and farming, carpentry and other technical work. Indoor : reading ; chess, draughts, and cards ; music. Another paper in the Contemporary, entitled "The Origin of Man and the Religious Sentiment," by A. Fogazzaro, invites criticism from the standpoint of erolution.

Prof. Case, Professor of Moral and Metaphysical Philosophy in Oxford University, champions the cause "Against Oxford Degrees for Women," in the Fortnightly. He holds that the admission of women to University examinations has brought out the difficulties of teaching mixed classes, and that a mixed University is not desirable, especially at Oxford. Let women have facilities for higher education, by all means, thinks Prof. Case, but let these opportunities be afforded by a University especially founded for women. Mr. Grant Allen writes on "The Mystery of Birth," in the same review, the object of his article being to raise the question, "Is there any real and essential difference between the transmission of functionally-acquired modifications to offspring, and their registration or persistence in the individual organism?" Disciples of Weismann, and biologists generally, will be interested to know that Mr. Allen proposes "to throw back upon assimilation, in its widest sense, the burden of the mystery hitherto attached to the reproductive function.

The Reliquary and Illustrated Archcoologist has among its articles one by Mr. H. W. Young, on the discovery of an ancient burial-place and a symbol-bearing slab at Easterton of Roseisle. A large number of flint instruments, such as arrow-heads, axes, scrapers, \&c., found associated with the remains, make the discovery interesting and important, especially in relation to the geology of the "Laich of Moray."

Natural science predominates in Science Progress this month. The pathological results of the Royal Commission on Tuber. culosis are discussed by Dr. Sidney Martin, and Mr. Arthur Keith uses Dr. Dubois' Pithecanthropus Erectus as a text for a helpful review of human fossil remains. The geology of the Sahara forms the subject of a paper by Mr. Philip Lake. As in July I 894 , Mr. Chree shows, in an extremely valuable table, the recent values of the magnetic elements at the principal magnetic observatories of the world. In an article entitled "A Type of Palæozoic Plants," Mr. A. C. Seward directs attention to the histological structure and affinities of the genus Calamites, and finally Dr. W. D. Halliburton describes the formation of lymph.

Among the articles in Knozvledge, we notice "The Sugar Cane," by Mr. C. A. Barber; "Scorpions and their Antiquity," by Mr. Lydekker, illustrated by two fine pictures of the giant sand-scorpion of Namaqualand, reproduced from photographs, and "The Great Nubecula," by Mr. E. W. Maunder. There are also articles on the field of diameter of the field of view of a telescope, Dr. Roberts' photographs of star-clusters and nebulæ, the cause of earthquakes, and on Prof. Fraser's experiments to find a cure for snake-bites.

Blackwoods Magazine contains a paper in which Colonel Knollys dwells upon public school and Army competitive examinations. He holds that the imperfections of the training at our public schools, and the character of some of the examination yapers, are responsible for the cramming now so common with candidates for the Army. Two other articles, in which our readers may be interested, are "Mountaineering Memories," by Mr. H. Preston Thomas, and "The Territorial Waters and Sea Fisheries."

A passing notice must suffice for the remaining articles of scientific interest in the magazines and reviews received by us. The Century has an article on "Picturing the Planets," by Prof. J. E. Keeler ; the article is illustrated by views of Jupiter, 